\title{
Xerostomia induced by radiotherapy
}

This article was published in the following Dove Press journal:

Therapeutics and Clinical Risk Management

5 August 2015

Number of times this article has been viewed

\section{David Alimi}

Department of Anesthesiology, University of Pittsburgh Medical Center, Pittsburgh, PA, USA
Correspondence: David Alimi Department of Anesthesiology, University of Pittsburgh, Pr. J. Chelly, Pittsburgh, PA, USA

Email davalimi7@gmail.com

\section{Dear editor}

We read with great interest the excellent review on xerostomia induced by radiotherapy, by Pinna et al. ${ }^{1}$ The authors should be congratulated for a very detailed review of the physiopathology, clinical symptoms, and therapeutic management of an extremely difficult condition. Although we agree that the use of anticholinergic medication represents a treatment, it requires the patient to have residual salivary gland function. Unfortunately, it is well established that in most cases radiotherapy destroys most of the salivary gland and associated salivary secretions. In these conditions, one therapeutic approach is to generate saliva by stimulating accessory salivary glands which are more resistant to radiation. This is due to histological differences between the main and accessory salivary gland. Thus, the accessory salivary glands have a short excretory duct, slightly or not branched whereas the main salivary glands, which are clearly differentiated, provide a larger intrinsic surface to radiation. This can be achieved with the use of auriculotherapy. In this regard we would like to point out a recent article by Alimi et $\mathrm{al}^{2}$ reporting that auriculotherapy can indeed be beneficial in this indication. Alimi et al conducted a parallel randomized single-blind placebo-controlled trial, with an independent observer in 60 patients suffering from dry mouth related to a xerostomia after radiotherapy of duration of 6 months or more. Patients were randomized to either auriculotherapy ("Alimi protocol": needle stimulations of six points of each auricle: VII nerve, IX nerve, cranial parasympathetic, anterior hypothalamus, point $\mathrm{O}$ and rhinencephalon) (Figure 1A and B) or placebo auriculotherapy. Primary end point was the absolute variation of dry mouth intensity measured on a visual analog scale. All the patients underwent three treatments at 1 -month intervals. The authors demonstrated that auriculotherapy improved dry mouth in $66 \%$ of patients, versus $4 \%$ of patients of the placebo group $(P<0.001)$. It is unfortunate that this therapeutic alternative was not referenced in Pinna et al's excellent review.

It is important for the readers to be introduced to the concept of auriculotherapy: evidence supports the concept that the placement of needle and/or cauterization of certain points of the ear has been used effectively for the treatment of various pathological conditions for thousands of years (antiquity: cabbalists, Chinese, ${ }^{3}$ ancient Egyptians, ${ }^{4}$ Hippocrates; ${ }^{4}$ middle ages: ${ }^{4}$ Turks, corsairs, Jerome Bosch; more recently, Dr Lusitanus, Dr Valsalva, Dr Luciani, Dr Malgaigne) ${ }^{4,5}$ In the 1950s Dr Paul Nogier (Lyon, France) observed on a number of his patients a cauterization of a specific point in the ear. Further investigation reveals that this had been performed by Madame Barrin, a healer, to treat sciatica. ${ }^{4}$ Dr Nogier later proposed the presence of an inverted homunculus on the ear and started to develop cartography of the ear in order to develop therapeutic protocols based on the specific 


\section{A Segmentograms of medial faces}

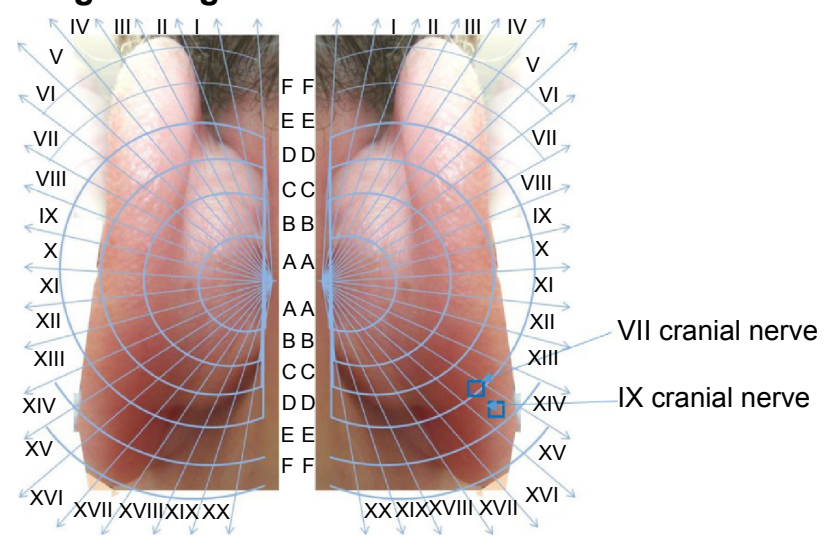

\section{B Segmentograms of lateral faces}
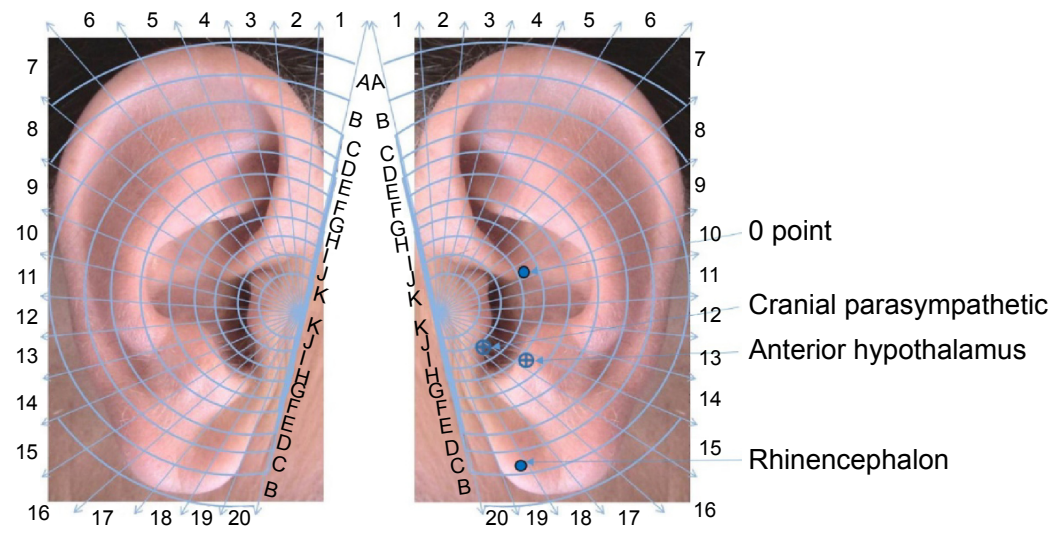

Figure I Alimi Protocol.

Notes: (A) Medial segmentogram with the indication of the points involved in the auriculotherapy of xerostomia. (B) Lateral segmentogram with the indication of the points involved in the auriculotherapy of xerostomia. Copyright $(\subset)$ David Alimi INPI October 2010.

stimulation of certain points of the ear. ${ }^{5,6}$ Drs Bourdiol $^{7}$ and Alimi ${ }^{8-11}$ further contributed to the development of a neurophysiopathology approach of using the ear as a way to stimulate a specific neurological pathway (Figure 2). The relationship between the cartography of the ear and the brain was confirmed by functional magnetic resonance imaging (fMRI) studies using the thumb, ${ }^{12}$ the brain stem, ${ }^{13}$ and the knee. ${ }^{14}$ This led to the modern definition of auriculotherapy: therapy with the goal of treating patients by the stimulation of reflexes originating in the auricle. In 2011 the International Classification which included 196 points in the ear was adopted by the World Federation of Chinese Medicine Societies ${ }^{15}$ (Figure 3).

For the development of auriculotherapy therapeutic protocols, a medical diagnostic and understanding of the physiopathology leading to the pathology for which the patient seeks treatment is required as a pre-requisite. In contrast, auricular acupuncture, a Chinese approach to the use of the

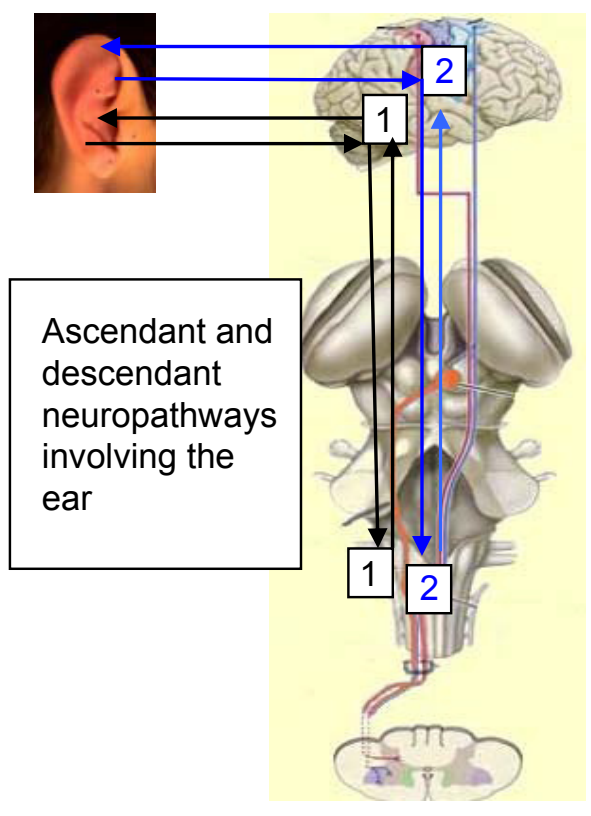

Figure 2 Schema showing the relations between neuropathways and the ear, as shown by the functional magnetic resonance imaging results. 


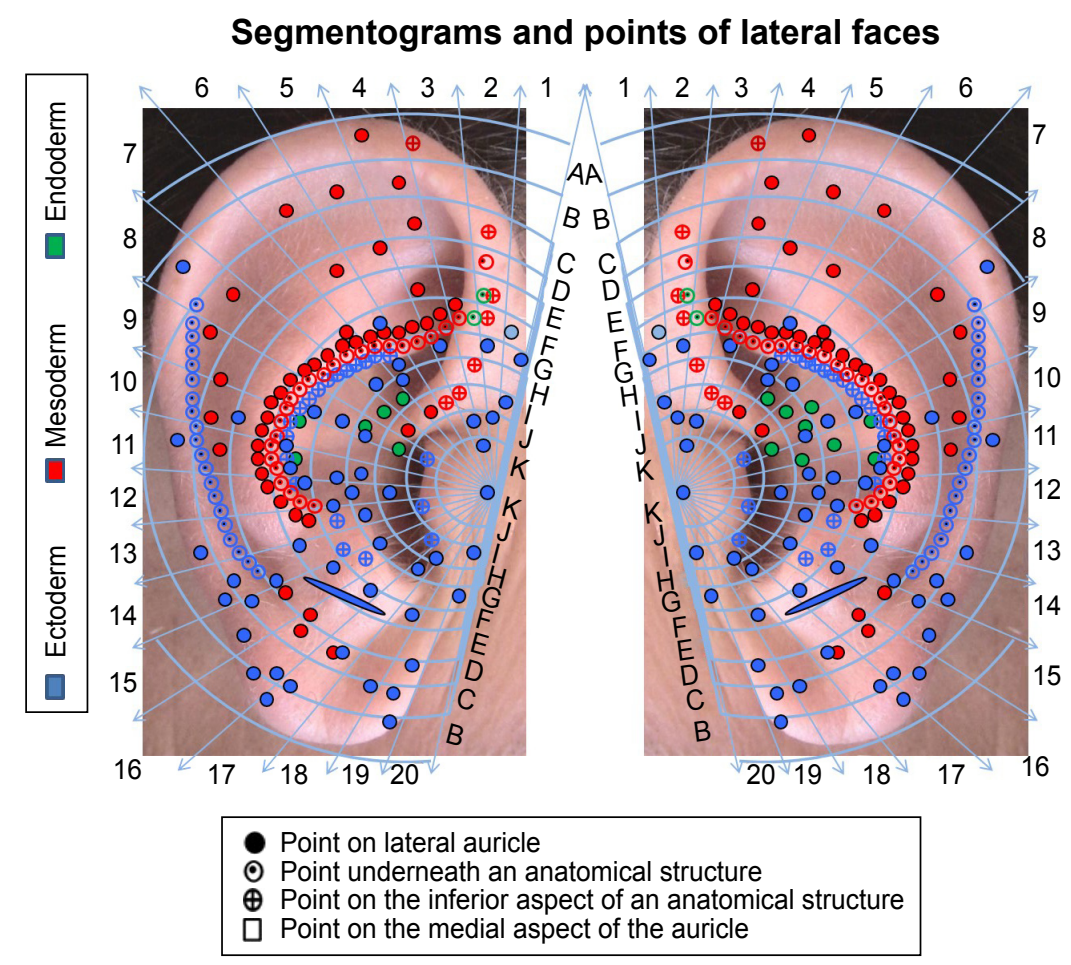

Figure 3 International nomenclature of auriculotherapy.

Notes: Showing the auricular points, in red: mesodermal points, in blue: ectodermal points, in green: endodermal points. Copyright @ David Alimi INPI October 20 I0.

auricle for therapeutic purposes, is based upon traditional Chinese medicine (use of meridians etc).

\section{Conclusion}

The author of this letter was the director of the Auricular therapy center for over 20 years at the Gustave Roussy Institute Pain Center in Paris, France and practiced auriculotherapy for more than 30 years. This therapeutic approach can be used with great success in cancer and non-cancer patients in many indications. ${ }^{16,17}$

\section{Disclosure}

The author has no conflicts of interest to disclose.

\section{References}

1. Pinna R, Campus G, Cumbo E, Mura I, Milia E. Xerostomia induced by radiotherapy: an overview of the physiopathology, clinical evidence, and management of the oral damage. Ther Clin Risk Manag. 2015;11: 171-188.

2. Alimi D, Poulain P, Brulé S, Véricel R, Cornillot P, Le Toumelin P. Randomized controlled study assessing the action of auricular acupuncture in xerostomia induced by radiotherapy of head and neck cancer tumors. Review of Odonto-Stomatology. 2012;41:245-259.

3. Dorfer L, Moser M, Bahr F, et al. A medical report from the stone age? Lancet. 1999;354(9183):1023-1025.

4. Gori L, Firenzuoli F. Ear acupuncture in European traditional medicine. Evid Based Complement Alternat Med. 2007;4(Suppl 1):13-16.
5. Rabischong P, Terral C. Scientific Basis of Auriculotherapy: State of the Art. Med Acupunct. 2014;26(2):84-96.

6. Nogier R. How did Paul Nogier establish the map of the ear? Medical Acupuncture. 2014;26(2):76-83.

7. Bourdiol R. Eléments d'Auriculothérapie. 1980; Ed. Maisonneuve.

8. Cho ZH, Oleson TD, Alimi D, Niemtzov RC. The Search for Biologic Evidence with Functional Magnetic Resonance Imaging and Positron Emission Tomography Techniques. J Altern Complement Med. 2002; 8(4):399-401.

9. Gaudy JF, Ahsan Ch-A, Alimi D, Brule S, Donnadieu S, Landru MM Manuel d'Analgesie en Stomatologie. Masson; 2005:193-201.

10. Alimi D, Brûlé S. Douleur en Oncologie. De Boecke; 2004:74-80.

11. Jacquemin D, De Boucker D, Alimi D, et al. Manuel de Soins Palliatifs. Dunod; 2014:285-292.

12. Alimi D, Geissmann A, Gardeur D. Auricular Acupuncture Stimulation Measured on Functional Magnetic Resonance Imaging. Medical Acupuncture. 2002;13:18-21.

13. Romoli M, Allais G, Airola G, et al. Ear acupuncture and fMRI: a pilot study for assessing the specificity of auricular points. Neurol Sci. 2014;35 Suppl 1:189-193.

14. Alimi D, Geissmann A, Gardeur D, Bahr F. Study in fMRI of the stimulation of the auricular areas of the knee as the French-German and Chinese localizations. Photon Journal of Radiology. 2014;125:133-141.

15. Nomenclature Normative Internationale -Edition Desclée de Brouwer; 2011:372-375.

16. Alimi D, Rubino F, Leandri EP, Brule SF. Analgesic Effect of Auricular Acupuncture for Cancer Pain. J Pain Symptom Manage. 2000; 19(2):81-82.

17. Alimi D, Rubino C, Pichard-Lewandowski E, Fermand Brûlé S, Dubreuil Lemaire ML, Hill C. Analgesic effect of Auricular Acupuncture for Cancer Pain: A Randomized Blinded Controlled Trial. J Clin Oncol. 2003;21(22):4120-4126. 
Dove Medical Press encourages responsible, free and frank academic debate. The content of the Therapeutics and Clinical Risk Management 'letters to the editor' section does not necessarily represent the views of Dove Medical Press, its officers, agents, employees, related entities or the Therapeutics and Clinical Risk Management editors. While all reasonable steps have been taken to confirm the content of each letter, Dove Medical Press accepts no liability in respect of the content of any letter, nor is it responsible for the content and accuracy of any letter to the editor.

Therapeutics and Clinical Risk Management

Dovepress

\section{Publish your work in this journal}

Therapeutics and Clinical Risk Management is an international, peerreviewed journal of clinical therapeutics and risk management, focusing on concise rapid reporting of clinical studies in all therapeutic areas, outcomes, safety, and programs for the effective, safe, and sustained use of medicines. This journal is indexed on PubMed Central, CAS,

EMBase, Scopus and the Elsevier Bibliographic databases. The manuscript management system is completely online and includes a very quick and fair peer-review system, which is all easy to use. Visit http://www.dovepress.com/testimonials.php to read real quotes from published authors.

Submit your manuscript here: http://www.dovepress.com/therapeutics-and-clinical-risk-management-journal 